\section{cift}

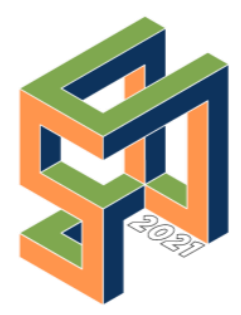

\section{SInGEURB}

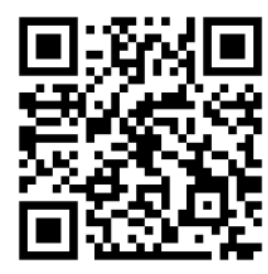

Como citar:

VIEGAS, Maria Ester Ferreira da Silva; SANTOS, Cirlene Jeane Santos. Cidade, capitalismo e sofrimento. In: III SIMPÓSIO NACIONAL DE GESTÃO E ENGENHARIA

URBANA: SINGEURB, 2021, Maceió. Anais... Porto Alegre: ANTAC, 2021. p. 6166.

Disponível em: https://eventos.antac. org.br/index.php/sin geurb/issue/view/14

\title{
Cidade, capitalismo e sofrimento
}

\section{City, capitalism and suffering}

Maria Ester Ferreira da Silva Viegas, Universidade Federal de

Alagoas/Campus Arapiraca, mestersilva@palmeira.ufal.br

Cirlene Jeane Santos Santos, Universidade Federal de Alagoas/Campus A.

C. Simões, cirlene@igdema.ufal.br

\section{RESUMO}

O artigo pretende discutir a condição dos deslocamentos populacionais forçados por causas ambientais, denominados "deslocados ambientais", ou "refugiados ambientais", oriundos do processo sociometabólico do capital. O afundamento e rachaduras no solo nos bairros do Pinheiro, Mutange, Bom Parto e Bebedouro que ganharam visibilidade a partir de 2018, estão associados a atividade extrativa realizada pela empresa Braskem S.A, que explora o Salgema. O Serviço Geológico do Brasil (CPRM), concluiu em laudo técnico que a principal motivação para o aparecimento das rachaduras é atividade extrativista realizada pela Braskem ao longo de mais de 4 décadas. $\mathrm{O}$ risco se instalou como normalidade atingindo uma população de mais de 40 mil vítimas em uma tragédia geológica de grandes proporções. O percurso metodológico partiu do levantamento documental e bibliográfico sobre a temática; observação de campo; e acompanhamento diário dos noticiários e informações gerais sobre o processo de mapeamento e retirada dos moradores. Concluímos que a discussão sobre o desaparecimento dos bairros citados, não se trata mais de um caso de análise econômica da natureza e sim de problemas decorrentes do avanço técnico e econômico, nos quais tem sido privilegiado os interesses do capital hegemônico corporativo em detrimento das populações e da sociedade em geral.

Palavras-chave: Cidade, Planejamento Urbano, Refugiados urbanos.

\section{ABSTRACT}

This article aims to discuss the disappearance of the Pinheiro, Bebedouro, Mutange and Bom Parto neighborhoods in the city of Maceió-Alagoas-Brasil. With a critical look at the construction of the city's urban planning during the period of military intervention in the country. The situation involves the phenomenon of sinking and cracking in the ground that gained visibility as of 2018, such processes are associated with the extractive activity carried out by the company Braskem SA, which exploits rock salt, a kind of sodium chloride used in the manufacture of $P V C$ and lye. In all, there are 35 wells maintained by Braskem in MaceióAl, 29 in operation and of these, 15 showed "changes in stability". Braskem's presence in Alagoas dates back to the 70s (at the time the company that installed itself there was called Salgema Indústrias Quimicas SA), during the government of then General Ernesto Geisel, during the military dictatorship, when the Development Plans were arbitrary in their genesis and execution. The chemical industry was used as one of the main flagships of military governments in terms of development.

Keywords: City, Urban Planning, Urban Refugees. 


\section{INTRODUÇÃO}

$\mathrm{O}$ artigo pretende discutir o desaparecimento dos bairros Pinheiro, Bebedouro, Mutange e Bom Parto na cidade de Maceió-Alagoas-Brasil, com um olhar crítico sobre intervenções no planejamento urbano da cidade durante o período da intervenção militar no país. A situação envolve o fenômeno de afundamento e rachaduras no solo que ganharam visibilidade a partir de 2018, tais processos estão associados a atividade extrativa realizada pela empresa Braskem S.A, que explora sal-gema, uma espécie de cloreto de sódio empregado na fabricação de PVC e soda cáustica. Ao todo são 35 poços mantidos pela Braskem em MaceióAl, 29 em operação e destes, 15 evidenciaram "mudanças na estabilidade". A presença da Braskem em Alagoas remonta aos anos 70 (à época a empresa que se instala no local denominava-se Salgema Indústrias Químicas S.A), no governo do então General Ernesto Geisel, durante a ditadura militar, nesse período os Planos de Desenvolvimento eram arbitrários na sua gênese e execução. A indústria química foi utilizada como um dos principais carros chefes dos governos militares no quesito desenvolvimento. $\mathrm{O}$ desaparecimento dos bairros incorre no surgimento de mais de 40 mil famílias em situação de deslocados, estes que estão sendo analisados como se fossem deslocados provenientes de um desastre ambiental natural, quando se configura como refugiados do desenvolvimento sócio metabólico do capital.

\section{CIDADE, CAPITALISMO E RISCOS URBANOS}

No contexto capitalista, o espaço urbano muda permanentemente, é constantemente remodelado pelo confronto contínuo entre forças sociais opostas, privilegiando, respectivamente, as dimensões de troca (lucro) e uso (vida cotidiana). Uma vez que a essência do capitalismo é a ganância e o egoísmo, não cabe aqui pensar na possibilidade da regulamentação das problemáticas da cidade, usando a imposição de regulamentações e de moralidade. Não há sustentabilidade na ordem do capital, o fluxo do capital que cria a riqueza de alguns, gera a dor e sofrimento de muitos.

Imagem 1. Acervo pessoal do autor.

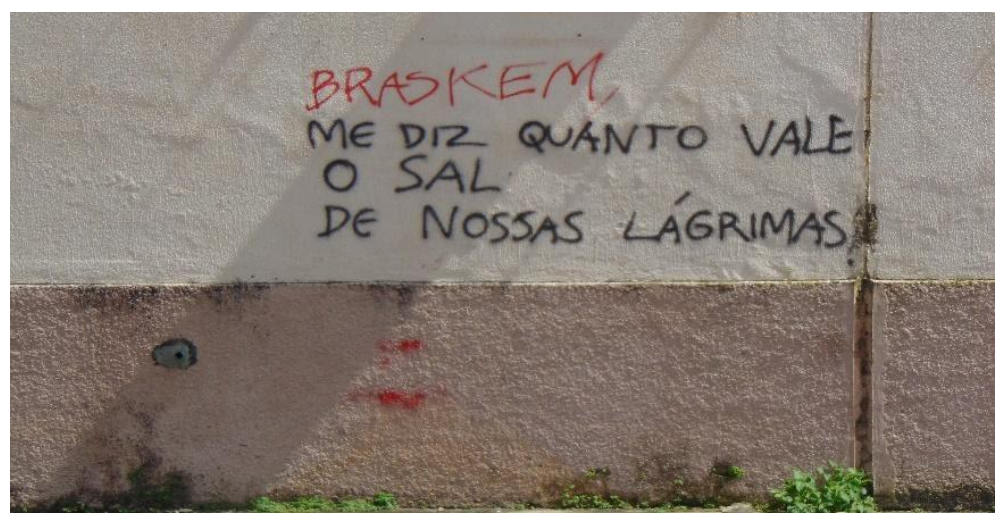

Fonte: Acervo pessoal do autor.

Segundo Harvey (2011) “a história do capitalismo está repleta de consequências ambientais indesejadas (por vezes de longa duração) algumas irreversíveis (como as extinções de espécies e de habitats) " e ele segue esmagando vidas e tradições. O afundamento dos bairros Bebedouro, Mutange, Pinheiro e Bom Parto é uma constatação de como o Estado e o Capital são os dois principais agentes modeladores do espaço, que produzem e reproduzem a segunda natureza. $\mathrm{O}$ afundamento dos bairros em discussão é um exemplo claro 
como a paisagem geográfica da acumulação do capital está sempre em transformação, em primeira medida sob o impulso das necessidades especulativas de maior acumulação, principalmente da especulação imobiliária e só secundariamente devido às necessidades das pessoas (Harvey, 2011 p.203).

É claro que as estratégias de reestruturação urbana com fins lucrativos são o assunto de uma luta intensa entre as forças sociais dominantes, subordinadas e marginalizadas. Além disso, as estratégias para comercializar o espaço urbano muitas vezes falham miseravelmente: elas resultam em paisagens urbanas e regionais degradadas, minadas pela crise, em que o trabalho e o capital são incapazes de formar uma aliança frutífera para atender às necessidades sociais, e em que o socioespacial existente as configurações são severamente abaladas, geralmente à custa de considerável sofrimento humano e degradação ambiental maciça. Ainda que essas estratégias de rentabilidade pareçam abrir novos horizontes para a obtenção de valor agregado, dentro das cidades, entre elas e fora dela, seu aparente "sucesso" esconde, na verdade, sucessos precários e temporários; a superacumulação, a desvalorização e a crise sistêmica continuam sendo desafios permanentes. No entanto, os conflitos, fracassos, instabilidades e tendências de crise associadas à urbanização capitalista não resultaram em sua dissolução ou superação, mas sim em sua constante reinvenção (processo sócio metabólico do capital) Apesar de suas consequências destrutivas e desestabilizadoras para a sociedade e o meio ambiente, a corrida frenética pelo lucro tem, portanto, desempenhado um papel essencial na produção e transformação das geografias urbanas.

As formas capitalistas de urbanização e suas consequências, tem sido desde a década de 1970 uma das preocupações analíticas e teóricas daqueles que discutem as formas urbanas e sua dinâmica. O capital fixo (particularmente aquele incorporado nos ambientes construídos), as finanças, o crédito, a renda, as relações de espaço e os gastos estatais, tudo isso tinha de ser reunido de maneira a se compreender melhor os processos urbanos, o setor imobiliário e os desenvolvimentos geográficos desiguais (Harvey, 2006). O processo de destruição dos bairros na cidade de Maceió, não pode ser lido como uma vingança da natureza. Harvey (2006) nos indica que a geografia da acumulação do capital e da destruição criativa na terra não pode ser sujeita a qualquer tipo de enfoque, que é necessário uma "análise cuidadosa desse tipo de dinâmica para entender melhor como funciona a coevolução em diferentes locais, primando por avaliar até que ponto a relação com a natureza constitui um limite à acumulação do capital" (HARVEY, 2011 p. 204-205).

A temática dos deslocados humanos oriundos de problemáticas socioambientais é atual e complexa, nos levando a perceber o quanto essa modalidade tem influenciado as migrações humanas. Segundo (Jubilut...et al. 2018), a abrangência da mesma se dá da seguinte forma: I - deslocamentos internos ou internacionais cujo gatilho são as questões ambientais, II - Deslocamentos causados por desastres naturais, decorrentes da ação humana ou da combinação entre ambas, III - Eventos súbitos ou decorrentes da degradação lenta do meio ambiente e IV - as consequências podem ser temporárias ou permanentes. Convém ressaltar que o fenômeno dos refugiados do desenvolvimento é resultante de causas de ordem econômica, afetando os aspectos cultural e social. O que tentaremos abordar no limite de espaço que permite essa construção textual é a processualidade da construção desses refugiados oriundos da atividade da mineração do Salgema pela Braskem na cidade de Maceió-Al/Brasil. A discussão colocada nesse artigo nos conduz a uma leitura geohistórica da instalação da referida mineradora na cidade de Maceió.

\section{A SALGEMA INDÚSTRIAS QUÍMICAS S. A - A INSTALAÇÃO}

No II PND[1] (Plano Nacional de Desenvolvimento) durante o governo militar de Ernesto Geisel, os eixos principais eram: a definição das estratégias, o traçado de uma política industrial e agrícola, a discriminação das competências do Estado e do mercado, as carências demográficas, a integração nacional, a ocupação produtiva do Norte, do Nordeste e do Centro-Oeste, os investimentos em infraestrutura e energia, 
problemas de poluição e meio ambiente, desenvolvimento urbano, planos de investimentos e financiamentos, emprego, programa nuclear e espacial e a articulação com a economia mundial.

A Salgema Indústrias Químicas S.A, se instalou em Alagoas começando a operar em 1976. Segundo Vieira (1977) ela inicia produzindo soda cáustica a partir do salgema, encontrado em grande quantidade nas minas do subsolo de Maceió, no bairro do Mutange, sendo uma proposta estratégica do plano desenvolvimentista do regime militar (II PND): industrialização via polos de desenvolvimento (Vieira, 1977 p.15). Em 1995 A Salgema, já era responsável por cerca de $40 \%$ da produção de soda cáustica e cloro do país. À época da instalação da Salgema em Maceió, gerou conflitos e mobilizou diferentes atores em defesa do seu lugar de moradia. A instalação da Salgema criava um conflito urbano envolvendo diferentes atores sociais, no caso os moradores do Pontal da Barra, em relação a duplicação do Salgema , na restinga do Pontal da Barra.

Em meados de 1980, Maceió tinha em média uma população de 478.345 habitantes, sendo caracterizada como uma cidade de porte médio, capital e sede administrativa do estado de Alagoas, bem cmo, por ser um entreposto de comercialização da produção agroindustrial do Estado (Vieira , 1977 p. 21). A proposta da instalação do Polo Cloroquimico no Estado,mas precisamente na área urbana da cidade de Maceió é descrita pelos poderes constituídos como uma grande alternativa de desenvolvimento da economia local, afirmavase que a integração da indústria sucro-alcooleira local a moderna indústria química, causaria um grande impacto na população alagoana , por conta de uma absorção de mão de-obra direta e indireta na ordem de 5.500 a 30 mil pessoas.(ibidem p. 23). É fato que causou um impacto muito grande na população do estado, com hoje uma população de mais de 40 mil vítimas das rachaduras nos bairros envolvidos nesse crime ambiental descomunal.

Segundo Vieira (1977) a decisão da localização da Salgema na restinga do Pontal da Barra resultou da tecnoburocracia ligada a Petroquímica e do então governador Afrânio Lages, com a implantação e funcionamento se efetivado no governo de Divaldo Suruagy, o empreendimento como já foi citado anteriormente, atendia aos objetivos do II PND e considerou para sua localização, a proximidade da matéria prima no subsolo de Maceió, e a facilidade de escoamento através do porto marítimo (Vieira, 19787 p.24). Cavalcante (2020) corrobora afirmando que:

“A instalação da Salgema Indústrias Químicas S.A , na restinga do Pontal da Barra, região Sul de Maceió, à beira mar e próximo ao encontro das águas do mar com a lagoa Mundaú, foi fruto da imposição em pleno regime militar. Não se levou em conta a expansão urbana da capital, o correto zoneamento industrial, o potencial turístico da região e o ecossistema lagunar. Não houve planejamento, nem observância do conceito de desenvolvimento sustentável. Prevaleceram o custo-benefício dos investidores, a força de Brasília e a cumplicidade das autoridades locais". (Cavalcante, 2020 p.25)

A Braskem surge de uma ação organizada da Odebrecht, com a criação de empresas no setor, compras de ativos em leilões, e aquisições de empresas. A Braskem é a empresa criada para aglutinar os investimentos realizados da década de 1990 a 2000 pela Odebrecht, e em um curto espaço de tempo se transformou na maior empresa petroquímica, a "Braskem é a maior produtora integrada de petroquímicos na América Latina", conforme destaca Hallot (2007, p. 39)

Atualmente ganhou destaque frente à iminência de um desastre sem precedentes nas terras alagoanas, contudo, desde o período de instalação da empresa que é questionada, não somente em relação a sua localização, mas também em relação aos métodos de extração do Salgema. 
Ticianeli (2019) descreve que os protestos sempre ocorreram desde o período de implantação da empresa, e voltavam a acontecer sempre que algum acidente ocorria. Os mesmos retornaram em 1985, com o "Movimento pela Vida", em função da proposta de ampliação da capacidade operacional da Salgema S. A.

\section{QUEM SÃO OS REFUGIADOS DO DESENVOLVIMENTO URBANO DA CIDADE DE MACEIÓ}

Os refugiados do desenvolvimento urbano de Maceió são os moradores afetados pela ação da mineradora, ao longo dos 45 anos de exploração do subsolo, em seus 35 poços de extração. Os bairros atingidos são Pinheiro, Mutange, Bebedouro e Bom Parto.

Diante do caos estabelecido, a Prefeitura de Maceió declarou estado de calamidade pública em 2019 e solicitou a intervenção do Governo Federal, este através da Ministério de Minas e Energia; Secretaria de Geologia, Mineração e Transformação Mineral; e Serviço Geológico do Brasil (CPRM), iniciaram as investigações cuja relatório final indica categoricamente que a causa da instabilidade geológica, repercutindo no afundamento do solo, foi a extração do Salgema ao longo dos anos. A extração do Salgema, acabou por ocasionar a formação de dolinas subterrâneas de enormes dimensões. O risco se potencializou, por estas ocorrerem em uma área de fraturas geológicas. Assim, além da subsidência que está ocorrendo no terreno, tem-se a possibilidade real dessas dolinas colapsarem, desabando, o que seria uma tragédia sem precedentes.

A área atingida é significativa e forçou o deslocamento compulsório de mais de 40 mil moradores, como já dito, segundo dados avulsos, pois estes não foram divulgados com precisão. Isso sem contar os inúmeros estabelecimentos comerciais, hospitais e clínicas que foram atingidos.

\section{CONCLUSÕES}

A situação posta na cidade de Maceió, capital de Alagoas, se traduz no descaso do poder público e na sua subserviência ao capital corporativo que assumiu as rédeas da exploração do Salgema ao longo do tempo à revelia das instituições públicas de fiscalização e controle ambiental. Não se comenta ou discute o porquê que a situação chegou a esse extremo. As instituições seguem silenciosas como se nada tivessem a ver com os fatos em curso.

O processo ainda está em curso, seguem os deslocamentos compulsórios dos moradores e as negociações indenizatórias. E os mapas das áreas atingidas seguem em uma constante atualização. A cada atualização do mapa novas áreas vão sendo incorporadas, ou seja, os moradores que não estão (ainda) com suas casas

no mapa da Braskem vivem apreensivos na incerteza se irão permanecer. O que causa ansiedade e aflição, levando os mesmos a processo de adoecimento.

\section{REFERÊNCIAS}

ALMEIDA, Alfredo Wagner Berno de. Refugiados do desenvolvimento: os deslocamentos compulsórios de índios e camponeses e a ideologia da modernização. In: Travessia. maio/agosto, 1996.

BECK, Ulrich. Sociedade de risco: rumo a uma outra modernidade. São Paulo: Ed. 34, 2010. 384p.

CAVALCANTE, Joaldo. Salgema: do erro a tragédia. Maceió: Editora CESMAC, 2020. 136p. 
COMDEC; CEDEC; SEDEC. Plano de ação integrado - Ações do Sistema Federal de Proteção e Defesa Civil para os bairros Pinheiro, Mutange e Bebedouro. Maceió-Al. Dezembro de 2019.

CPRM. Respostas do Serviço Geológico do Brasil aos Questionamentos da Braskem - Questões encaminhadas pela Braskem ao Serviço Geológico do Brasil na audiência com o Ministério Público Federal,em 3 de Junho de 2019a, em Maceió, AL.

CPRM. Estudos sobre a instabilidade do terreno nos bairros Pinheiro, Mutange e Bebedouro, Maceió (AL): Relatório Síntese dos Resultados no 1, 2019b.

DERANI, Cristiane. Refugiado ambiental. In: Dicionário de Direitos Humanos. Brasília, 6 jun. 2006. Disponível em: http://escola.mpu.mp.br/dicionario/tikiindex.php?page=Refugiado+Ambiental\#: :text=Refere $\% 2 D s e \% 20$ a $\% 20$ pessoas $\% 20 q u e, p a \% C 3 \% A D s \% 20 p$ ara\%20outro\%20buscando\%20ref\%C3\%BAgio. Acesso em: 10 fev. 2021.

HALLOT, Felipe Antunes Maciel. Consolidação do setor petroquímico brasileiro avaliando a Braskem. Orientador: João Manoel Pinho de Mello. 2007. 83 p. Monografia de Final de Curso (Graduação em Economia) - Departamento de Economia, Rio de Janeiro, 2007.

HARVEY, David. O Enigma do Capital e as crises do capitalismo. Editora Bizâncio. Lisboa.2011.

. Os Limites do Capital. Editora Boitempo. São. Paulo.2013

ÍNTEGRA.MCZ. n: Facebook. Maceió- AL: @Integra.mcz. Disponível em: https://www.facebook.com/integra.mcz/. Acesso em: 10 fev. 2021.

JUBILUT, Liliana Lyra ... (et alii). Refugiados Ambientais. organizadoras; Amanda Allgayer ... (et alli) - Boa Vista: Editora da UFRR, 2018. 932p.

RAMOS, Érika Pires. Refugiados Ambientais: em busca de reconhecimento pelo direito internacional. Orientador: Alberto do Amaral Júnior. 2011. 150 p. Tese (Doutorado em Direito) - Universidade de São Paulo - Faculdade de Direito, São Paulo, 2011.

TICIANELI, Edberto. Descoberta de sal-gema em Alagoas foi por acaso. In: História de Alagoas. MaceióAL: Edberto Ticianeli, 22 nov. 2015. Disponível em: https://www.historiadealagoas.com.br/descoberta-dasal-gema-em-alagoas-foi-por-acaso.html. Acesso em: 10 fev. 2021.

TICIANELI, Edberto. Salgema e o movimento contra a ampliação de 1985. In: História de Alagoas. MaceióAL: Edberto Ticianeli, 1 abr. 2019. Disponível em: https://www.historiadealagoas.com.br/salgema-e-omovimento-contra-a-ampliacao-de-1985.html. Acesso em: 10 fev. 2021.

VIEIRA, Maria do Carmo. Daqui só saio o pó: Conflitos urbanos e mobilização popular: a Salgema e o Pontal da Barra. Maceió:EDUFAL, 1997. 96p.

[1]Fonte: em linha retirado do site: https://www.ipea.gov.br/. Acessado por Maria Viegas em 31 de janeiro de 2021. 